IZA DP No. 4685

Labour Contract Regulations and Workers' Wellbeing: International Longitudinal Evidence

Andrea Salvatori

January 2010 


\title{
Labour Contract Regulations and Workers' Wellbeing: International Longitudinal Evidence
}

\author{
Andrea Salvatori \\ ISER, University of Essex \\ and IZA
}

\section{Discussion Paper No. 4685 \\ January 2010}

IZA

P.O. Box 7240

53072 Bonn

Germany

Phone: +49-228-3894-0

Fax: +49-228-3894-180

E-mail: iza@iza.org

Any opinions expressed here are those of the author(s) and not those of IZA. Research published in this series may include views on policy, but the institute itself takes no institutional policy positions.

The Institute for the Study of Labor (IZA) in Bonn is a local and virtual international research center and a place of communication between science, politics and business. IZA is an independent nonprofit organization supported by Deutsche Post Foundation. The center is associated with the University of Bonn and offers a stimulating research environment through its international network, workshops and conferences, data service, project support, research visits and doctoral program. IZA engages in (i) original and internationally competitive research in all fields of labor economics, (ii) development of policy concepts, and (iii) dissemination of research results and concepts to the interested public.

IZA Discussion Papers often represent preliminary work and are circulated to encourage discussion. Citation of such a paper should account for its provisional character. A revised version may be available directly from the author. 
IZA Discussion Paper No. 4685

January 2010

\section{ABSTRACT \\ Labour Contract Regulations and Workers' Wellbeing:
International Longitudinal Evidence}

All industrialized countries have Employment Protection Legislation (EPL) for permanent workers and Restrictions on the use of Temporary Employment (RTE). The (ambiguous) effects of these on the levels of employment and unemployment have been extensively studied, but nothing is known empirically about their well-being implications. Using longitudinal data from the European Community Household Panel, the author conducts the first study of the link between both EPL and RTE and workers' wellbeing. The results provide evidence that both permanent and temporary employees gain from reforms that ease restrictions on temporary employment but leave firing costs for permanent workers unchanged. This finding contrasts with common claims found in the political economy literature.

JEL Classification: J28

Keywords: $\quad$ temporary employment, employment protection legislation, job satisfaction

Corresponding author:

Andrea Salvatori

Institute for Social \& Economic Research

University of Essex

Colchester CO4 3SQ

United Kingdom

E-mail: asalva@essex.ac.uk

\footnotetext{
* I thank prof. Mark Stewart and prof. Andrew Oswald for many helpful discussions. Useful comments were also provided by participants in seminars at Warwick University, WPEG London seminar series, the 2006 Congress of Italian Labour Economists, CEPS/INSTEAD, Differdange, Luxembourg, international conference on "Policies for Happiness", University of Siena, Italy. Access to the ECHP was obtained within an EPUNET visit at the ESRI, Dublin, Ireland and as an IRISS visitor at CEPS/INSTEAD, Differdange, Luxembourg. I also thank the Directorate for Employment, Labour and Social Affairs of the OECD for providing the time-series of the EPL indicator used in this paper. Financial support in the form of EST Marie Curie Fellowship from the European Union is gratefully acknowledged. The ECHP data can be purchased from Eurostat while computer programs used can be obtained from the author.
} 


\section{Introduction}

In the last twenty years, several countries have eased restrictions on temporary employment while leaving firing costs for permanent workers substantially unaltered. Freeman (2005) provides a review of the papers studying the (ambiguous) effects of these reforms on labour market performance, but nothing is known on their welfare consequences for the employed. Yet, understanding the welfare implications of these regulations is necessary to deal with the potential trade-off between providing protection that is valued by workers and ensuring that future job creation is not undermined. This paper presents the first study of the effects on individual workers' wellbeing of employment protection legislation (EPL) for permanent workers and restrictions on the use of temporary employment (RTE).

Because changes in labour contract regulations affect workers in potentially offsetting ways, it is not possible to draw welfare implications simply on the basis of traditionally observed variables. For example, changes in the degree of protection might not result in changes in wages or employment status, but might significantly alter future job prospects and therefore workers' current wellbeing. In order to overcome this problem, Blanchard and Landier (2002) use data on wages and transition probabilities to construct an "empirical counterpart" of utility to assess the welfare effect of the introduction of fixed-term contracts in France. This paper pursues a different avenue and explores the use of subjective wellbeing data. Di Tella and MacCulloch (2006) and Kahneman and Krueger (2006) stress that such data can be particularly useful in settings where observed behavior has ambiguous welfare implications.

While permanent employees are considered as well, the main focus of the analysis is on temporary workers. In recent years, such group of workers has been at the center 
of an academic and policy debate fueled by the evidence that they often suffer poorer worker conditions (OECD, 2002; Booth et al., 2002; Arulampalam and Booth, 1998; Arulampalam et al., 2004; Kahn, 2007; Brunello et al., 2007). Particularly interesting for the purpose of this paper is the finding of Booth et al. (2002) that temporary workers report lower satisfaction with several aspects of their jobs in the UK. For the same country, Bardasi and Francesconi (2004) report no long-term negative effects of limitedduration contracts, while Petrongolo (2004) finds lower job satisfaction among temporary workers across Europe and especially in Southern countries. The evidence presented in this paper can therefore begin to shed some light on whether regulations designed to protect permanent workers and restrict the use of temporary employment can play a role in improving temporary workers' wellbeing.

The analysis uses measures of job satisfaction which have been found to correlate with workers' wellbeing (Warr, 1999; Argyle, 2001) and to predict quits (Freeman, 1978; Clark, 2001; Lévy-Garboua et al., 2007). I estimate job satisfaction equations using micro panel data on a large sample of temporary and permanent employees from 7 waves of the European Community Household Panel (ECHP). I control for country unobserved heterogeneity and time effects and allow individual random effects. While the nonlinear nature of the model advises against fixed effects, I also use a correlated random effects model (Mundlak, 1978) to allow for some correlation between (individual) unobserved heterogeneity and the included regressors. EPL and RTE are measured by using the newly released time-series indicators produced by the OECD (2004) and potential differences in their effects across the private and public sectors are explored.

Significant effects are found almost exclusively for temporary workers. The robustness of such results is further investigated using subsamples by gender, age and geographical 
location. Furthermore, country-specific time trends are allowed and measures of satisfaction with different aspects of one's job are used to try and disentangle the channels through which RTE and EPL may affect temporary workers' overall satisfaction.

Using ECHP data, Clark and Postel-Vinay (2009) have previously found a negative link between job security and regulations, as measured by a cross-sectional indicator averaging EPL and RTE (OECD, 1999). As I am interested in evaluating the overall wellbeing effects of labour contract regulations, I adopt a more general measure of wellbeing (i.e. job satisfaction) rather than focusing on job security. Moreover, I look at the effects of EPL and RTE separately as the two exhibit different degrees of variation and I intend to capture the consequences of reforms changing the two sets of regulations in different ways. Finally, the EPL and RTE indicators I use vary both across countries and over time. The focus on the effects of the two dimensions of legislation on both temporary and permanent employees is also what differentiates this paper from Wasmer (2006) who uses Canadian data on permanent employees to find a positive correlation between the stringency of protection and job stress.

The main conclusion of the paper is that reforms that ease RTE but leave EPL unchanged are positively correlated with wellbeing of both temporary and permanent workers, particularly for women and the young. To the extent that wellbeing gains translate into support for given policies, this finding is not consistent with the common assumption in the political economy literature that only permanent workers oppose reforms that relax EPL. 


\section{Employment protection legislation and restrictions to the use of temporary employment}

This paper presents one of the first applications of the new regulation indicators proposed in OECD (2004). The OECD overall indicator of regulation results from the aggregation of 18 basis indicators concerning three broad areas of regulation: 1) regular contracts 2) temporary contracts and 3) specific requirements for collective dismissals. A time series is only available for the first two. I refer to the first as employment protection legislation (EPL) and to the second as restrictions on temporary employment (RTE).

The basic indicators aggregated to obtain the EPL index concern the procedural difficulties faced by the firm in firing a worker, the strictness of the definition of unfair dismissal, and the notice period and severance pay in case of no-fault dismissal. The RTE index measures restrictions to the use of fixed-term and temporary work agency workers, namely (i) limitations to cases where these workers can be employed, (ii) limits to the number of renewals and (iii) limits to the cumulative duration of temporary contracts. Details on how the indicators are constructed can be found in OECD (2004) along with a descriptions of the main changes in legislation occurred in each country over the last twenty years.

Previous cross-sectional versions of the OECD indicators have been used, among others, by Blanchard and Wolfers (2000); Kahn (2007). Nicoletti et al. (2000) used factor analysis to find that the 1999 version of the indicator is not particularly sensitive to different weighting schemes while Addison and Teixeira (2003) have shown that it correlates well with other measures of rigidity constructed from employers' answers to surveys and even with more broadly defined indicators of economic freedom. 
Figure 1 plots the time-series of EPL for 14 European countries. Portugal and the UK stand out as the most rigid and the most flexible countries respectively. The graph clearly shows that while there is a certain level of cross-country variation, the time-series variation has been rather limited over the last decade both in terms of the number of and the scope of the changes occurred. Seven countries have changed this set of regulations. Four of them (Finland, Spain, Denmark and the Netherlands) have eased restrictions on firing permanent workers, while the remaining three (UK, France, and Belgium) have strengthened them. Quite a different picture is shown in figure 2 where the time-series of RTE are plotted. Most of the countries which have brought about changes have relaxed the stringency of these regulations. Out of the seven countries for which a change in RTE is recorded, only for Spain does this change show a positive sign. While the UK and Ireland stand out as the most flexible countries in the use of temporary employment, Italy and Belgium appear to have brought about the most dramatic changes in their legislation moving from the top of the chart to the middle of it.

\section{Theoretical literature}

The theoretical framework most commonly adopted to model regulations for both temporary and permanent workers is the matching model (Wasmer, 1999; Pissarides, 2000; Blanchard and Landier, 2002; Cahuc and Postel-Vinay, 2002; Cahuc and Zylberberg, 2004). In this framework the life-time expected utility of risk-neutral workers is a function of their instantaneous utility in different labour market status and of the probabilities of moving across them. The general equilibrium effects of regulations on permanent and temporary contracts are complex when job destruction is endogenous because they affect

worker's utility (i) directly, (ii) through the transition probabilities, and (iii) through the 
wage $^{1}$.

The direct effect follows from severance pay being a component of these regulations, at least for permanent workers. Changes in transition probabilities take place because regulations on hiring temporary workers or firing permanent workers obviously affect both job creation and job destruction. Finally, regulations affect workers' bargaining strength and the value of the outside options (via their effect on transition probabilities) therefore altering the wages resulting from bargaining.

Most of the papers, however, model regulations for the two types of contracts as different firing costs, whereas in reality regulations on temporary contracts do not normally take such form. An exception is Cahuc and Postel-Vinay (2002), where a fixed-term contract entails no firing costs but there is a legal restriction on the number of employees who can be hired on a temporary contract. In this set up, the higher the firing cost for permanent workers, the lower the conversion rate from fixed-term to permanent contracts implying that the destruction rate of temporary jobs increases. Moreover, less severe restrictions on the use of temporary contracts increase both job creation (because temporary jobs, not entailing firing costs, yield a higher surplus) and job destruction (because the improvement in the outside option following the increase in job creation increases the threshold productivity below which a match is ended), with the latter effect being particularly strong when firing costs are high. They therefore obtain a theoretically ambiguous effect on the welfare of the employed who are faced with both an increase in the value of unemployment (because of the increase in the exit rate from unemployment) and an increase in the probability of becoming unemployed.

Insider-outsider models can also provide insights on the effects of firing costs on work-

\footnotetext{
${ }^{1}$ As noted by a referee, the relative importance of changes in future and current states of the world will depend on the discount rate as well.
} 
ers' wellbeing. Clearly, firing costs enable permanent workers to obtain higher wages and extra-wage benefits when bargaining with the firm, leading to an increase in their wellbeing. Moreover, as pointed out by Dolado et al. (2002), the presence of temporary workers can provide a protective buffer for permanent workers further increasing their bargaining strength. Hence, regulations restricting the use of temporary workers can have negative effects on permanent workers' wellbeing. In line with the literature which sees permanent workers as the insiders, the literature on the determinants of EPL has generally taken the view that temporary workers, not being directly protected by such regulations, are part of the pool of outsiders who oppose stringent protection for the insiders. When this point is not made explicitly as in Dolado et al. (2002), it appears to be implicit in the argument whereby the political support for EPL comes exclusively from those directly protected by it (Saint-Paul, 2002; Boeri et al., 2003).

Wasmer (2006) has a theoretical model with permanent workers alone where the stringency of employment protection induces firms to increase the intensity of their monitoring with an increase in stress for the workers. In order to induce voluntary quits which are not subject to firing costs, firms will also worsen working conditions for workers in matches which in the absence of regulations would be ended. In this framework, the effect of employment protection on workers' wellbeing is therefore negative.

Finally, a common feature of the models described above is that workers are riskneutral. When workers are risk-adverse, the mere stability of a job arising from higher legal protection can positively affect workers wellbeing. However, since regulations on temporary employment take the form of limits to the use of these types of contracts, it is not obvious how such regulations affect risk-adverse temporary employees. 


\subsection{Theoretical predictions}

Based on the literature reviewed in the previous section, I can summarize the hypotheses on the effects of regulations on permanent workers' wellbeing.

1. The effect of restrictions on temporary employment on permanent worker's wellbeing is negative. This is because RTE reduce job creation leading to a more stagnant labour market, increase the exposure of permanent workers to demand fluctuations, and limit the strength of permanent insiders hindering their ability to obtain higher wages and non-wage benefits.

2. The effect of protection for permanent contracts on permanent worker's wellbeing is ambiguous. A more stagnant labour market reduces the value of the outside option, but EPL protects workers from the risk of unemployment and increases their bargaining strength. If firms respond to the firing costs by increasing the monitoring of the workers, their stress can increase and their wellbeing decrease.

To formulate predictions of the effects of regulations on temporary workers' wellbeing, the arguments from the theoretical models have to be integrated with intuition taking into account what exactly the indicators used in the empirical analysis measure.

1. The effect of restrictions on temporary employment on temporary workers' wellbeing is ambiguous. RTE lead to a stagnant labour market, increasing the risk of unemployment when the contract expires. They also make it more difficult to have a contract renewed, but this can also potentially increase the probability of moving into permanent employment. Finally, more restrictions can decrease permanent insiders' strength in the bargaining process, improving temporary workers' relative conditions. 
2. The effect of protection for permanent contracts on temporary workers' wellbeing is ambiguous. While EPL increases permanent workers' strength and makes unemployment more stagnant, temporary employees might be willing to accept current insecurity in exchange for future higher protection.

Finally, in spite of the theoretical uncertainty on the precise effect of regulations on temporary workers' wellbeing, the general assumption in the political economy literature on the determinants of regulations is that temporary employees oppose protection for permanent workers, presumably because that reduces their utility by lowering their chances to enter the protected segment of the labour market.

\section{Empirical literature}

The vast majority of the empirical literature explicitly considering both EPL and EPL has focused on their effects on labour market performance. The bulk of the evidence suggests that relaxation of regulations for temporary contracts does not necessarily lead to an improvement of labour market conditions (OECD, 1999, 2004; Blanchard and Landier, 2002; Dolado et al., 2002; Freeman, 2005). Among the few empirical studies which have tried to investigate the wellbeing effects of regulations are Blanchard and Landier (2002); Clark and Postel-Vinay (2009); Wasmer (2006).

Blanchard and Landier (2002) attempt to evaluate the welfare effects of the introduction of fixed-term contracts in France. They construct a measure of the average expected present value of utility using available information on income and transition probabilities across different states and conclude that there is some evidence of a negative effect of these reforms on young workers' welfare. 
Clark and Postel-Vinay (2009) study satisfaction with security of male respondents in the last five waves of the ECHP. Regulations are measured by the OECD (2004) cross-country indicator aggregating both EPL and RTE. They use a latent class model to account for selection of workers into different types of jobs and find a negative relationship between (overall) regulations and perceived job security for temporary and permanent workers.

Wasmer (2006) looks at the wellbeing effects of firing costs on permanent workers alone. Using longitudinal individual data for Canada over the period spanning from 1994 to 2003, he finds that regional variation in employment protection (for permanent workers) is positively correlated with job stress, concluding that stricter legal protection reduces workers' wellbeing.

\section{Job satisfaction as a measure of workers' wellbeing}

The brief review of the theoretical literature in the previous sections has highlighted the complexity of the effects of regulations on workers' utility. Di Tella and MacCulloch (2006) discuss the usefulness of subjective wellbeing data for policy evaluation in settings like the present one where the theoretical link between behavior and welfare is ambiguous. The use of subjective wellbeing measures in welfare analysis has been recently advocated by Kahneman and Krueger (2006) while Layard (2006) discusses the policy implications of the subjective wellbeing literature. Among the papers which have explicitly used subjective indicators as proxy for utility in economics are Vendrik and Woltjer (2007), Luttmer (2005), Ferrer-i Carbonell (2005), Blanchflower and Oswald (2004), Tella et al. (2003), Clark (2003), Frey and Stutzer (2002), Di Tella et al. (2001), and Clark and Oswald (1996). 
All of these authors obviously acknowledge the caveats of such measures. Kahneman and Krueger (2006) point out that since subjective wellbeing data reflect people's perceptions of their experiences, they are not necessarily a measure of utility as traditionally conceived by economists. They also discuss how people's answers may be affected by context and mood, but do not see these issues as disqualifying such measures especially in large representative samples. Easterlin (2001) presents similar arguments along with others based on the psychology literature supporting comparability across countries of self-reported wellbeing. Moreover, Kahneman and Krueger (2006) stress that subjective wellbeing measures have been found to predict certain behaviors and to correlate in expected ways with characteristics of individuals. As the authors point out, this applies to the measure adopted in this paper, i.e. job satisfaction, which has been found to predict quits (Freeman, 1978; Clark, 2001; Lévy-Garboua et al., 2007). Hamermesh (2001) sees this as a compelling reason to study job satisfaction. Other economics papers using job satisfaction include Heywood et al. (2002), who investigate the satisfaction of union members and public sector employees, and Booth et al. (2002), who finds that temporary employees are less satisfied than permanent employees.

Warr (1999) and Argyle (2001) review the psychology evidence on the link between job satisfaction and overall wellbeing. They also discuss the literature finding that job satisfaction correlates in meaningful ways with many individual and job characteristics and with other behaviors such as absenteeism, job performance and employees' willingness to help coworkers and their organization. As I am interested in the effects of labour market regulation, the use of job satisfaction as a wellbeing variable appears intuitive. Furthermore, the ECHP does not contain more general wellbeing questions, nor am I aware of other international and longitudinal datasets containing wellbeing measures. The 
maintained assumption is simply that reported job satisfaction is a monotonic function of underlying wellbeing. Since I intend to assess the overall effect of legislation on workers' wellbeing, the main focus of the paper is on overall job satisfaction rather than satisfaction with specific aspects of one's job.

In the ECHP workers are asked to rate their overall satisfaction with their job on a scale from 1 to 6 . Moreover, they are asked about their satisfaction with specific aspects of their jobs. I try to exploit this information to understand the channel through which regulation can affect overall job satisfaction of temporary workers. The basic assumption is that overall job satisfaction can be written as:

$$
J S_{i}^{*}=\sum \gamma_{j} S a t_{j i}^{*}+\varepsilon_{i}
$$

where $S a t_{j i}^{*}$ is satisfaction of individual $i$ with aspect $j$ of her job. The star indicates that this continuos measure of satisfaction is a latent variable that is not actually observed by the researcher who only sees its mapping into a discrete variable, i.e. reported job satisfaction. Overall job satisfaction is therefore seen as the linear combination of satisfaction in different domains.

\section{The empirical model}

\subsection{Data}

The ECHP is a standardized longitudinal survey which was carried out between 1994 and 2001 in all member states of the EU under the coordination of Eurostat. It includes information at the household and individual level in a wide range of topics (income, employment, health, housing etc.). A detailed description of the dataset and a discussion 
of the methodological issues involved is in Peracchi (2002).

I restrict the sample to individuals aged between 16 and 65 and working either on a permanent or temporary contract ${ }^{2}$. Data from 13 countries are used in the analysis, leaving out Sweden and Luxembourg for which job satisfaction is missing. For Germany, the job satisfaction question was only asked to the ECHP-specific sample in the first three waves. Moreover, the German sample does not have information about the region of residence, which means that I cannot use that country at all when including regional unemployment as a covariate. The regional unemployment rates come from the REGIO database of EUROSTAT and were matched with the regional identifier available in the $\mathrm{ECHP}^{3}$. Since data from the first wave do not include information on the type of contract of a worker, the empirical analysis only uses data from waves 2 to 8 .

\subsection{The econometric model and specification}

I employ an individual random effects ordered probit to take into account (i) the longitudinal structure of our data and (ii) the ordinal nature of the dependent variable ${ }^{4}$.

\footnotetext{
${ }^{2}$ The variable contract type is only available for employees working at least 15 hours per week, leading to an unavoidable underrepresentation of part-time workers in the final sample. A rough look at the full sample (pooling all data and waves together) reveals that we are indeed excluding $30 \%$ of part-timers. However, those individual represent less than $4 \%$ of the total number of employees in the ECHP. Finally, it should be noted that when we look at individuals working more than 15 hours, we see that there are more part-timers among temporary workers (11\%) than among permanent workers (7\%). Therefore, by excluding those working less than 15 hours, we are likely to be excluding more temporary than permanent workers.

${ }^{3}$ In some cases, the level of aggregation did not coincide between the two datasets. Where the ECHP presented regions at a lower level than the REGIO datasets, each region was assigned the same unemployment rate.

For some regions, data were missing for the first year (1994), while they were available at a higher level of aggregation. In such cases the data for 1994 were reconstructed as follow: first, the average ratio between the regional unemployment and that of the larger region within which that region is contained was calculated over the available years; then the missing data were obtained by applying the same ratio to the unemployment rate of the larger region in the year for which the data were missing.

For The Nederlands and Denmark the unemployment rate is the national unemployment rate. This is also for most regions of Portugal and for Ireland excluding Dublin. For Italy, the unemployment rates for the macro regions of the ECHP were calculated as simple averages of the available data for the individual regions.

${ }^{4}$ Estimation is conducted using the gllamm programme in STATA 9.2 (Rabe-Hesketh et al., 2004).
} 
The random effects specification assumes that the individual heterogeneity is independent of the included regressors and normally distributed with mean zero and constant variance. Since the nonlinearity of the ordered probit means that a fixed effects estimator would remain inconsistent ${ }^{5}$, I resort to a correlated random effects model (Mundlak, 1978) whereby the individual-level mean of unobserved heterogeneity is set equal to the within-individual mean of the time varying regressors. All specifications, however, do include country fixed effects and time effects.

Standard errors are corrected for clustering at the country level because of the presence of the EPL and RTE indicators. This remains necessary even after the inclusion of country fixed-effects as by pooling countries together any cross-country heterogeneity in the slope coefficients is effectively relegated into the error term (Wooldridge, 2003). I adopt conservative critical values because the small number of clusters might lead to downward biased standard errors (Wooldridge, 2003), an aspect often neglected in the applied literature ${ }^{6}$. Table 1 shows that in a specification including only exogenous regressors, the correlation between the regulation variables and job satisfaction exhibits the same sign for permanent and temporary workers. In particular, satisfaction of both types of workers is positively associated with stronger protection for permanent workers and negatively with restrictions on temporary employment. Statistical significance, however, is not always obtained. The rest of the paper tries to shed more light on the link between regulation and wellbeing by including additional controls and by focusing on different groups for which different results might be expected.

Common to all the specifications adopted is the inclusion of the following standard

\footnotetext{
${ }^{5}$ Greene (2007) reviews some of the recent attempts to control for fixed effects in an ordered logit including the application to job satisfaction by D'Addio et al. (2007).

${ }^{6}$ When regional controls are included, I still adopt a correction for country-level clusters as that leaves the within-cluster (regional) correlation unrestricted. Clustering at levels that do not nest individuals (i.e. by country and year) is not possible given the presence of individual random effects.
} 
controls for job satisfaction equations: age, age squared, female, part-time, married, education, occupation and industry dummies ${ }^{7}$, a dummy for (self-reported) health problems, log of hours worked per week, dummies for the presence of children in the household and job status dummies (supervisory, intermediate or other). Due to the high number of missing values (in particular for some countries) I am unable to include other potentially relevant controls such as firm size (as reported by the employees) and extra-wage benefits.

The first specification I use does not include a control for the wage. Following the theory, this is meant to let the legislation indicators capture the direct and indirect effects of regulations on satisfaction.

In the second specification I include the log of monthly real net wage (in PPS) to look at the effect of regulation for a given wage. I then include the regional unemployment rate as a control variable. I expect it to capture features of the local labour market which go beyond those determined by EPL and RTE for two main reasons: in the first place legislation is defined at the national level (although it might be argued that its enforcement differ across regions), while countries exhibit quite large cross regional variations in unemployment; in the second place, theory predicts that the effect of EPL on unemployment is ambiguous and empirical studies do not find a clear correlation between unemployment and EPL. In a parallel and independent paper studying the effects of protection for permanent workers on job stress, Wasmer (2006) follows a similar approach. Moreover, the inclusion of local unemployment is in line with the work on happiness and life satisfaction of Di Tella et al. (2001) and Blanchflower and Oswald (2005).

\footnotetext{
${ }^{7}$ Since computation time is proportional to the squared of the number of parameters when using gllamm (Rabe-Hesketh et al, 2004), we adopted a parsimonious specification including only 2 industries dummies for Industry and Services instead of the 16 which ideally we could have included. Not surprisingly, when the full set of available industry dummies was included using our smallest samples, the results did not change in any relevant way.
} 


\subsection{Are these policy changes exogenous?}

If the variation in labour contract regulation is exogenous, the correlations found in the regressions can be given a causal interpretation. Endogeneity can arise because of correlation between the regressors and either the unobserved individual heterogeneity or the residual job satisfaction. Absence of correlation between individual heterogeneity and labour market regulation is a reasonable assumption after controlling for country fixed-effects and time effects. In fact, differences in national legislation are likely to reflect cultural differences across countries, rather than personality differences across individuals ${ }^{8}$.

As for the potential correlation with residual job satisfaction, in this panel data setting, consistency requires that current shocks must not be correlated with past, present and future EPL and RTE. If one thinks of the error term as a pure uncorrelated idiosyncratic shock affecting job satisfaction in each period (as in a correctly specified model), then it is clear that it cannot be correlated with past legislation. Moreover, contemporaneous correlation appears unlikely given that in all countries procedures to change national legislation are rather lengthy (Brügemann, 2007).

Arguably, even future legislation is unlikely to be correlated with a past transitory shock given the complexity and duration of the reform process. Legislation is likely to reflect structural features of a national labour market rather than past transitory shocks. In particular, labour market reforms of EPL and RTE were encouraged by the consensus view in international organizations as one (if not the) instrument to tackle high and persistent unemployment, at least for some demographic groups such as the young and women (Freeman, 2005). This suggests that unemployment and demographic character-

\footnotetext{
${ }^{8}$ For example, Algan and Cahuc (2006b,a) explain differences in EPL across countries using crosscountry differences in civic attitudes and religion.
} 
istics are likely to be among the main determinants of labour policies. Controlling for these variables, as I do in at least some of the specifications, should therefore help remove these confounding effects.

It is still possible, however, that other institutional changes I am unable to control for might have occurred at the same time as EPL or RTE changes. As in any cross-country study it is virtually impossible to satisfactorily control for every other institutional aspect or to find suitable instruments affecting exclusively EPL and RTE. I attempt to mitigate the problem (i) by including country and time effects and (ii) by investigating the possible role of unemployment benefits when discussing our results. The latter is, in fact, the institutional aspect which is arguably most likely to play a role similar to that of employment protection in insuring the worker against the risk of unemployment.

Finally, a word of caution on the sense in which selection into contract types can pose a problem for the analysis of this paper. The possibility that people with inherently different levels of wellbeing might select themselves into different contract types is a relevant concern if one looks at differences in wellbeing across contract types. In this paper, on the other hand, the focus is on the effects of regulations on wellbeing within contract types. Hence, the assumption maintained throughout the analysis is that the strictness of EPL and RTE does not interact with unobserved heterogeneity in the process that determines selection into different contracts. While I do not attempt to relax such assumption, as previously mentioned, I check the robustness of the results in a correlated random effect model (Mundlak, 1978) that allows some correlation between the individual effects and the included regressors. 


\section{$7 \quad$ Results for permanent workers}

Table 2 reports the results for job satisfaction for permanent workers. Column 1 shows that when the wage is omitted, the EPL and RTE attract a positive and a negative sign respectively, but both fail to reach statistical significance. When the wage is included, the coefficients on the regulation variables change slightly. In particular, while protection for permanent workers remains positive but statistically insignificant, restrictions on temporary employment are now significant at the $10 \%$ level, a result that must be taken with caution given the possible downward bias of the standard errors due to the small number of clusters in the data (Wooldridge, 2003). Column 3 illustrates that when the individual unobserved component is allowed to be correlated with the included regressors, similar results are obtained for the regulation variables, with RTE now on the verge of statistical significance at the $5 \%$ level $^{9}$.

To interpret the magnitude of these coefficients, rather than looking at marginal effects which vary across the distribution of the unobserved heterogeneity, it is informative to compare the relevant coefficients to that on log of wage. Our estimates indicate that an increase in firing restrictions from the lowest level (.95 in the UK) to the median level (2.61 in Spain) has the same effect on the distribution of reported satisfaction as an impressive $58 \%$ increase in real wage. Similarly, an increase in restrictions on temporary employment from the lowest level (.25 in Ireland and UK) to the median value $(3.25$ in Spain) is equivalent to a $36 \%$ cut in wage. These estimates must be read bearing in mind that a number of personal and job characteristics are being controlled for therefore making the effect of real wage on satisfaction relatively small, as commonly found in the

\footnotetext{
${ }^{9}$ Results from a linear model with fixed effects are qualitatevely similar, with EPL attracting a statistically insignificant postive coefficient and RTE a statistically significant negative one.
} 
literature (Easterlin, 2001). Finally, when unemployment is controlled for (column 3), the two regulations change only marginally and local unemployment itself shows a negative but insignificant coefficient.

To summarise, since our estimates fail to reach satisfactory levels of statistical significance, I am not able to draw strong conclusions from these results. However, I do find that in our sample permanent workers' satisfaction is positively correlated with firing restrictions and, as expected from economic theory, negatively correlated with restrictions to the use of temporary employment.

\subsection{Public and Private Sector Employees}

The specifications considered so far included a dummy for the public sector to capture systematic differences between the two sectors in reported satisfaction. However, there are reasons to suspect that regulation may affect employees from the two sectors in different ways. In the first place, public sector employees are not exposed to the same kind of uncertainty as their private sector counterpart (i.e. demand fluctuations) and therefore, even in the presence of the same degree of legal protection, the actual relevance of such protection may differ sharply between the two sectors. In the second place, several countries have different regulations concerning public employees and the extent to which this is taken into account by the OECD (2004) indicator employed in this analysis is not clear. To allow the effect of regulation to differ between private and public sector, I interact the regulations variables with the dummies for private and public sector and then I test whether these coefficients are different using a robust Wald test. The results are reported in table 3. Protection for permanent workers confirms a positive sign for both private and public sector employees, but it again fails to reach statistical significance even 
at the $10 \%$ level. The Wald test fails to reject the null the two coefficients are different.

RTE, on the other hand, exhibits a positive and insignificant coefficient for public sector employees, but a negative and strongly significant coefficient in the private sector. The statistically week result described for the full sample in the previous paragraph seems therefore to be entirely driven by the private sector. The Wald test supports the conclusion that the effect of regulations on temporary employment differ between the private and public sector.

Economic theory suggests that RTE may have negative effects on permanent workers' wellbeing because they reduce (permanent) insiders' strength and increase their exposure to labour market fluctuations. Since public sector employees are inherently less exposed to labour market forces, the finding that regulations on temporary employment only affects private sector permanent employees seems consistent with the theory. On the other hand, these different findings for the private and public sector can be seen as evidence that the indicator being used is actually a good measure of legal protection, as it correlates with job satisfaction in different ways for different workers as expected.

\section{Results for temporary workers}

\subsection{Job Satisfaction}

I begin by looking at the job satisfaction equation for fixed-term workers in table 4 . Column one shows that the overall effect of RTE on fixed-term workers' satisfaction is negative and statistically significant at the $1 \%$ level, while that of protection for permanent workers is positive but far from reaching statistical significance at any conventional level. 
The introduction of the real wage into the specification in column 2 does not alter the results for the regulation indicators and I can again reject the null of a zero coefficient on RTE even at the most conservative level. The coefficient is slightly larger than in the previous specification and comparison with that on log of real wage reveals that the Italian reforms (the largest in Europe over the period considered) were equivalent to a $44 \%$ increase in real wage. These apparently large effects are mainly driven by the limited effect of real wage on job satisfaction, once items such as education and occupation are controlled for (Easterlin, 2001). Column 3 in table 4 shows that the results do not change substantially if some correlation is allowed between the unobserved heterogeneity and the included (individual-level) regressors ${ }^{10}$.

When the specification is extended to include local unemployment, this latter exhibits a negative and significant coefficient and the coefficients on both types of regulations increase in magnitude with that on EPL now reaching statistical significance at the $5 \%$ level. As previously discussed, the inclusion of the unemployment variable causes the loss of all observations for Germany, but several checks performed with a pooled ordered probit indicate that the significance of the EPL variable in this specification is not driven by the different sample used ${ }^{11}$. The size of the coefficients implies that an increase from the minimum level of restrictions (0.95 in the UK) to the median level (2.61 in Spain) is equivalent to a $75 \%$ increase in real wage.

In all the specifications considered so far, country effects are controlled for and year effects allow for flexible common time trends. Given the limited underlying variation and the relatively short period of time I am able to exploit, it is obviously difficult to

\footnotetext{
${ }^{10}$ Results from a linear model with fixed effects confirm a negative and statisticaly significant coefficient for RTE. On the other hand, EPL attracts a negative coefficient, but remain highly statistically insignificant.

${ }^{11}$ These results are available from the author upon request.
} 
empirically distinguish between the effect of changes in legislation and possible underlying country-specific trends. The results in the last column of table 4 are therefore not surprising. The coefficient on RTE, which is consistently negative and significant in all previous specifications, shrinks and, although still negative, becomes statistically indistinguishable from zero This casts doubts on the robustness of our results, but in light of the amount of variation I can exploit to identify both trends and legislation effects, one could argue that I am asking too much of the data. Additional evidence could come from longer periods of time or from identification strategies exploiting within-country variation in legislation, although objections could always be raised concerning the possibility of non-linear and/or regional trends.

Table 5 shows that the negative sign of RTE is found both in Northern and Southern Europe. Statistical significance is clearly attained for the Southern countries, while for Northern Europe the inclusion of France seems to matter, making the coefficient on RTE insignificant. As for EPL, the limited variation in the indicator means that the effect is again rather imprecisely estimated with the sign of the coefficient changing depending on how North and South are defined. There is some evidence, however, that the positive correlation found when using all countries is mainly driven by Southern European countries.

When job satisfaction equations are estimated separately for males and females, the negative and significant sign on RTE is only found for females, as shown in columns 1 and 2 of table 6 . This result, coupled with the lower coefficient on income for women, leads to the striking result that the Italian labour market reforms were equivalent, in terms of job satisfaction, to a $95 \%$ increase in wage. Similarly, in columns 3 and 4 I find that only young temporary employees are negatively affected by RTE and since their satisfaction 
seems to be relatively little sensitive to income, the estimated coefficients imply that the Italian reforms are equivalent to a $59 \%$ increase in wage, whereas for adults the figure is $27 \%$ (but note that the coefficient on the regulation variable does not reach statistical significance).

To summarize, our results provide evidence of a negative relationship between restrictions on temporary employment and wellbeing of temporary employees in particular for women and the young. Such result is robust to the inclusion of country effects and flexible common trends, but, given the limited variation available, statistical significance is lost when country-specific time trends are allowed. I have also obtained some evidence of a positive correlation between protection for permanent workers and temporary workers' satisfaction, which appears large in magnitude and statistically significant when unemployment is controlled for. These results seem to be driven by countries in Southern Europe.

\subsection{Domain Satisfaction}

I now turn to measures of satisfaction in different domains to investigate whether the correlations found in the previous section are driven by some factors that I have not been able to control for, namely job security and working conditions. If such items correlate with satisfaction and regulations affect either or both, the regulation indicators would pick up their effects in the overall job satisfaction equations. In the absence of objective indicators in my dataset, looking at satisfaction with these items is as far as I can go in trying to understand whether the effect of regulations is taking place through job security or working conditions.

Theory makes clear that both protection for permanent workers and restrictions on 
temporary employment affect job creation and job destruction therefore affecting temporary workers' security. As for working conditions, if by improving their own, permanent workers affect working conditions for temporary workers, then regulations affecting the strength of permanent workers will be correlated with temporary workers' working conditions. Following the insider-outsider logic mentioned in the theory section, this reasoning can be applied to both EPL and RTE.

\subsubsection{Satisfaction with Security}

Table 7 shows that when the dependent variable is satisfaction with security, the coefficients on both regulation variables turn out positive but statistically insignificant, but when unemployment is included in the specification, EPL becomes highly significant ${ }^{12}$. This finding is consistent with the interpretation provided above whereby currently temporary workers value the security they will enjoy once on a permanent contract. In particular, the local unemployment variable can be seen as a proxy for the difficulty of getting a stable job. After removing such effect, temporary workers's wellbeing is positively affected by future protection. On the other hand, the statistical and economic insignificance of RTE suggests that job security is not the channel through which such regulations affect overall job satisfaction.

When I look at satisfaction with security separately for men and women, I find that EPL attracts a positive and significant coefficient for both genders providing additional support to the hypothesis that temporary workers are positively affected by protection for permanent workers. The results in table 7 also show that RTE is positive for men, but

\footnotetext{
${ }^{12}$ When the model without the unemployment variable was ran on the same sample as the model with unemployment, the same results were obtained. This suggests that the difference in results between the two specifications is not driven by a difference in the sample being used. These results are available upon request.
} 
negative for women and in both cases not statistically significant. Temporary employees in the public sector report lower satisfaction with security than their private sector counterpart regardless of their gender.

\subsubsection{Satisfaction with working conditions and type of work}

Table 8 shows that there is no evidence that the overall negative correlation between RTE and temporary employees' satisfaction is driven by satisfaction with working conditions or type of work. EPL, on the other hand, seems to be positively correlated with these two domains, especially with satisfaction with working conditions. This suggests that better working conditions might be an additional channel through which this dimension of regulation affects temporary workers' job satisfaction. An outsider-insider interpretation would argue that there are positive spillovers from protected permanent workers to temporary workers, for example because the improvements obtained by permanent workers are workplace specific rather than job specific.

\subsection{Public and Private Sector Employees}

I ran a specification to allow the effect of regulation to differ between the private and the public sector to take into account the fact that the two sectors face inherently different kinds of uncertainty. Adopting the strategy previously described for permanent workers, I obtained the results reported in table 9 for job satisfaction (column 1 and 2) and satisfaction with security (column 3 and 4 ).

I find clear evidence that the negative effect on job satisfaction of RTE is driven by the private sector temporary employees. For the public sector the effect is still negative but not significant and a robust Wald test allows us to reject the null of the effect being 
constant between sectors. The difference in the effect of regulations might be explained by the different reasons for using temporary employment in the two sectors. In particular, because of the very nature of public sector jobs it seems likely that temporary jobs in this sector are not used to deal with demand uncertainty. If this is the case, then public sector temporary employees are likely to be less concerned with the implications of restrictions on the use of temporary contracts.

When looking at satisfaction with security, I again find that controlling for local unemployment both public and private sector temporary employees seem to benefit from higher protection for permanent employees. The Wald test cannot reject the null hypothesis that both regulation variables have the same effect in the two sectors. RTE do not seem to have a significant effect on temporary worker's satisfaction with security, in some cases attracting a positive sign, as opposed to the negative one found in the job satisfaction equations. This again suggests the surprising fact that the effect of employment protection on workers' satisfaction does not run through satisfaction with security.

\section{Discussion of results}

This paper has found only statistically weak evidence that stricter protection translates into higher job satisfaction for permanent workers. The lack of precision of the estimates might well be due to the limited variation of the indicator used in the analysis, but the failure to pick up a well-defined positive wellbeing effect of EPL is in line with previous results by Wasmer (2006) and Clark and Postel-Vinay (2009). The former uses panel data and regional variation in EPL for Canada and finds a positive correlation with job stress, whose statistical significance is however lost when regional dummies are included. Using ECHP data, the latter finds a negative link between a cross-sectional general indicator 
of regulation (an average between EPL and RTE) and job security.

There is statistically more robust evidence that permanent workers' wellbeing is negatively correlated with restrictions to temporary employment (RTE). These correlations can be given a causal interpretation if one postulates that constant differences in legislation are explained by country-fixed effects and changes in legislation are explained by variations in unemployment and demographic characteristics. This result is consistent with the only clear-cut prediction I gathered from reviewing the theoretical literature. In fact, restrictions on temporary employment may have a negative effect on permanent workers' wellbeing because they reduce (permanent) insider's strength and increase their exposure to labour market fluctuations. Moreover, stricter regulations mean a more stagnant labour market and consequently a lower expected value of unemployment.

As for temporary workers, I find evidence that their job satisfaction decreases when restrictions on the use of temporary employment increase. The result is statistically very well defined even when country effects and a flexible common trends are controlled for, but statistical significance is lost when country-specific time trends are included. Given the limited underlying variation this is hardly surprising and further evidence could come from longer time periods or studies using within-country variation in legislation. The negative correlation is found both in Northern and Southern Europe, but statistical significance is stronger in the South. Moreover, the results appear to be driven by the private sector and they are found to hold for the young and women, consistently with the argument that flexibility benefits these groups. A more stagnant labour market caused by heavy regulation can explain this result, given that fixed-term workers need to find another job at the end of their contract. Moreover, stricter restrictions make it harder for temporary workers to have their contract renewed. However, I find no evidence of 
a negative relationship between RTE and satisfaction with job security which suggests that the effect of RTE unfolds through a different channel. Similarly, working conditions and type of work do not seem to be driving the negative correlation of RTE with job satisfaction, as I find no evidence of a negative effect of RTE when looking at satisfaction with these items.

A possible explanation is that RTE affects the extent to which temporary contracts are voluntarily chosen by workers by limiting the possibility of renewals or the cumulative duration of contracts. To investigate this hypothesis I have turned to two other datasets uncovering some evidence in support of an inverse relationship between RTE and voluntary temporary employment. First, I have used Eurostat aggregate data on the share of voluntary temporary employment for a panel of 16 European countries over the years from 1993 to 2002. I find that, controlling for EPL, RTE explains the increase in temporary employment across countries, but not within-countries ${ }^{13}$. Second, I use microdata on individuals from 14 EU countries from a 2002 Flash Eurobarometer survey. These cross-sectional results indicate a negative correlation between RTE and the probability of being a voluntary temporary employee, after controlling for a wealth of personal and job characteristics ${ }^{14}$.

I also find some weak evidence that protection for permanent workers increases job

\footnotetext{
${ }^{13}$ Data were obtained from Eurostat New Cronos (Theme 3), ESDS International, University of Manchester. Voluntary temporary employment is defined as the share of temporary employees who "did not want a permanent job". Involuntary temporary employees are those who "could not find a permanent job". Correlation between RTE and the share of (involuntary) voluntary temporary employment is significantly (positive) negative, but becomes positive and isignificant when country fixed effects are included.

${ }^{14}$ Data from Flash Eurobarometer 120, obtained through the German Social Science Infrastructure Service (http://www.gesis.org/en/data_service/eurobarometer/flash/index.htm). Sample size varies from 700 to 1000 depending on the definition of temporary workers. Data from 14 European countries in 2002. Voluntary temporary employees are those reporting to work on a limited-duration contract "on a voluntary basis". Estimation by probit with standard errors corrected for country-clusters on the sample of temporary employees. The negative sign on RTE is significant when estimation is not weighted, but not when weights for EU-15 are used (note that 14 countries are actually used in the estimation).
} 
satisfaction for temporary employees, particularly in Southern European countries. When investigating the reasons for this correlation I find the same results for satisfaction with working conditions and satisfaction with security. Following the insider-outsider logic, the first result can be explained by positive spillovers from stronger permanent workers to temporary workers, especially if improvements in working conditions are workplacespecific rather than job-specific. As for satisfaction with security, the result appears surprising because temporary workers are not protected by EPL, but it is possible that temporary workers anticipate the higher protection they will receive once on a permanent contract.

Finally, in a tentative excercise not reported here, I have augmented the specification of the job satisfaction equation by including the estimated probabilities ${ }^{15}$ of (i) becoming unemployed and (ii) becoming unemployed and receiving unemployment benefits (UB). The latter is an attempt to control for another institutional feature which may play a role similar to that of EPL in insuring the worker against unemployment. Both for permanent and temporary employees this does not alter the signs of the regulation variables. In addition, the inclusion of an interaction term between EPL and the estimated probability of moving into a permanent job provides some indication that temporary workers who are more likely to switch to a permanent job are positively affected by EPL. Albeit statistically weak ${ }^{16}$, this is consistent with my interpretation of the positive effect of EPL on temporary workers' satisfaction with security as being driven by the anticipation of likely future protection.

\footnotetext{
${ }^{15}$ Due to the lack of credible exclusion restrictions, transition probabilities are estimated using a multinomial logit model with ECHP data adopting the same specification as the job satisfaction equations. Standard errors are not corrected for generated regressors, but the statistical insignificance of most results makes such correction substantially irrelevant.

${ }^{16} \mathrm{EPL}$ is negative and insignificant, while the interaction term is positive and insignificant. RTE mantains a negative sign which is significant at the $1 \%$.
} 


\section{Conclusions}

This paper has presented the first empirical evidence on the wellbeing effects of firing costs for permanent workers and restrictions on temporary employment.

I found evidence that private sector permanent employees are negatively affected by RTE. The economic theory I have reviewed suggests that RTE reduces permanent insiders' strength and increases their exposure to labour market fluctuations.

Temporary workers' satisfaction is negatively correlated with RTE, particularly for the young and women. There is no evidence that such effect comes through job security or working conditions, while tentative evidence suggests that RTE might reduce the share of voluntary temporary employment.

Temporary workers' satisfaction is positively correlated with protection for permanent workers, especially in the private sector and at least in Southern European countries. Results on satisfaction with working conditions point to possible positive spillovers from stronger permanent workers to temporary workers, for example because workplace improvements are made. Also satisfaction with security of temporary workers increases with EPL, suggesting that temporary workers might be anticipating future protection they will enjoy once on a permanent contract.

Overall, this evidence is consistent with the hypothesis that both permanent and temporary employees gain in terms of wellbeing from reforms lowering exclusively RTE. To the extent that wellbeing gains translate into support for a given policy, the results suggest that temporary employees are likely to be in favor of reforms which do not relax EPL even if they are not directly protected by it.

Since these results refer to individual workers, one should be careful about drawing inferences on the effects of EPL and RTE reforms on aggregate wellbeing. In particular, 
not withstanding the findings of this paper, reforms making it easier to create temporary jobs need not lead to an increase in aggregate satisfaction. In fact, since temporary workers generally report lower satisfaction, the increase in the share of temporary employment generated by such reforms (Kahn, forthcoming) can actually result in a net negative effect on aggregate satisfaction. A very simple regression of average job satisfaction (by country and year) on RTE and EPL shows that the coefficients of the regulation variables change only very marginally when the share of temporary employment is controlled for. This preliminary piece of evidence suggests that the indirect effect of regulations on average satisfaction through the share of temporary employment is likely to be negligible. An indepth analysis of this point certainly requires a more careful consideration of the possible changes in the demographic composition of permanent and temporary employment caused by variations in EPL and RTE (Kahn, 2007). In addition, a full assessment of the effects of such reforms on aggregate wellbeing should also take into account the unemployed as their expected utility will be affected by changes in job creation and destruction as well. This, of course, requires a measure of wellbeing other than job satisfaction, which is not available in the dataset used in this paper. Nevertheless, this is certainly an interesting and promising area for further research. 


\section{Figures}

Figure 1: Employment protection legislation for permanent workers, OECD (2004) Indicator

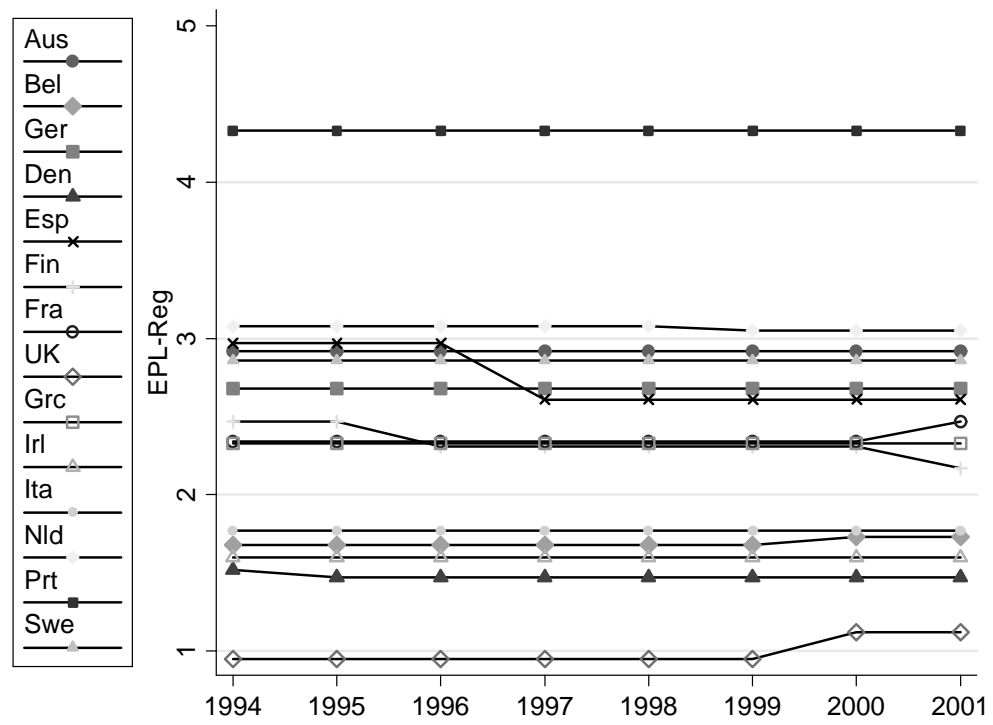


Figure 2: Restrictions on temporary employmenr, OECD (2004) Indicator
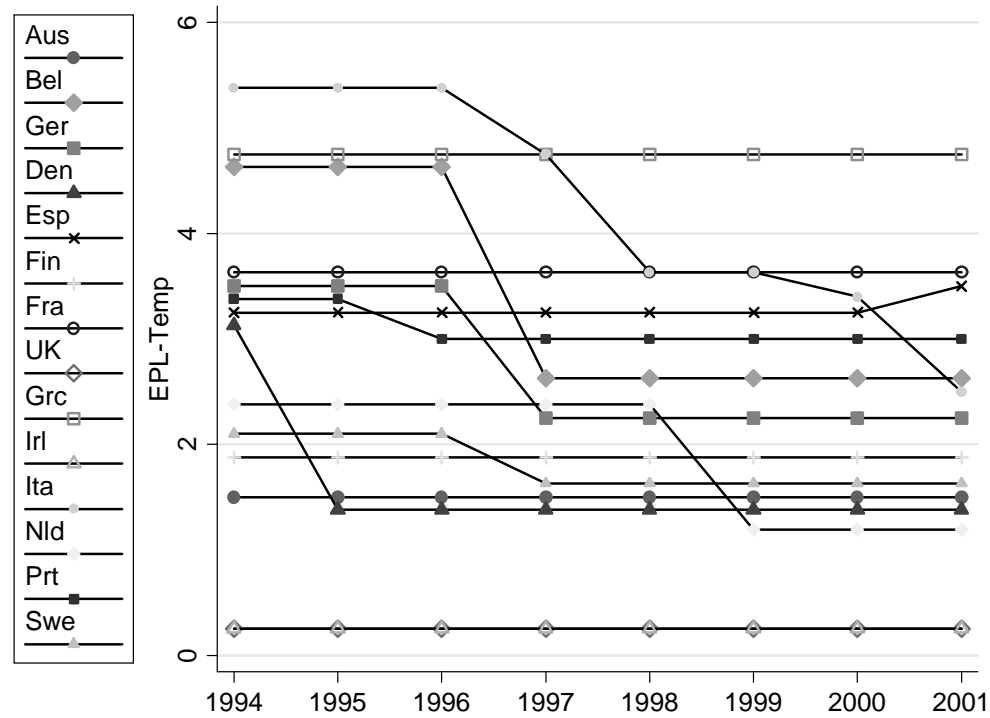

\section{Tables}

Table 1: Random Effests Ordered Probit: Job Satisfaction Equations for Permanent and Temporary Employees.

\begin{tabular}{|c|c|c|c|}
\hline Variable & \begin{tabular}{l}
\multicolumn{1}{c}{ Perm } \\
Job Sat \\
Coef./SE \\
\end{tabular} & $\begin{array}{c}\text { Temp } \\
\text { Job Sat } \\
\text { Coef./SE } \\
\end{array}$ & $\begin{array}{c}\text { Temp } \\
\text { Sat w/ Security } \\
\text { Coef./SE }\end{array}$ \\
\hline Age & $\begin{array}{l}-.012 \\
(.011)\end{array}$ & $\begin{array}{c}-.016^{* *} \\
(.007)\end{array}$ & $\begin{array}{c}-.084^{* * *} \\
(.016)\end{array}$ \\
\hline Age2 & $\begin{array}{l}.000 \\
(.000)\end{array}$ & $\begin{array}{l}.000 \\
(.000)\end{array}$ & $\begin{array}{c}.001^{* * *} \\
(.000)\end{array}$ \\
\hline Female & $\begin{array}{l}.052 \\
(.033)\end{array}$ & $\begin{array}{c}.086^{* * *} \\
(.023)\end{array}$ & $\begin{array}{c}-.102^{* * *} \\
(.031)\end{array}$ \\
\hline EPL & $\begin{array}{l}.153^{*} \\
(.092)\end{array}$ & $\begin{array}{c}.055 \\
(.064)\end{array}$ & $\begin{array}{c}.131 \\
(.123)\end{array}$ \\
\hline RTE & $\begin{array}{l}-.014 \\
(.014) \\
\end{array}$ & $\begin{array}{c}-.052^{* * *} \\
(.018)\end{array}$ & $\begin{array}{l}.023 \\
(.042) \\
\end{array}$ \\
\hline \multicolumn{4}{|c|}{ Year and Country Dummies included } \\
\hline $\begin{array}{l}\text { Significance } \\
\text { SE adjustec }\end{array}$ & $\begin{array}{l}\text { vels: }{ }^{*} 10^{0} \\
\text { r country }\end{array}$ & $\begin{array}{l}* * 5 \% \text { * } * * \\
\text { lusters }\end{array}$ & $\%$ \\
\hline
\end{tabular}


Table 2: Random Effects Ordered Probit:Job Satisfaction Equations for Permanent Employees.

\begin{tabular}{|c|c|c|c|c|}
\hline & 1 & 2 & $3^{a}$ & 4 \\
\hline & Job Sat & Job Sat & Job Sat & Job Sat \\
\hline \multirow[t]{2}{*}{ Age } & $-.040^{* * *}$ & $-.054^{* * *}$ & $-.024^{* *}$ & $-.053^{* * *}$ \\
\hline & $(.009)$ & $(.007)$ & $(.012)$ & $(.008)$ \\
\hline \multirow[t]{2}{*}{ Age2 } & $.001^{* * *}$ & $.001^{* * *}$ & .000 & $.001^{* * *}$ \\
\hline & $(.000)$ & $(.000)$ & $(.000)$ & $(.000)$ \\
\hline \multirow[t]{2}{*}{ Child } & .014 & .016 & -.005 & .015 \\
\hline & $(.017)$ & $(.018)$ & $(.010)$ & $(.018)$ \\
\hline \multirow[t]{2}{*}{ Married } & $.049 * * *$ & $.038^{* * *}$ & $-.034^{* *}$ & $.041^{* * *}$ \\
\hline & $(.012)$ & $(.013)$ & $(.017)$ & $(.013)$ \\
\hline \multirow[t]{2}{*}{ Female } & -.004 & $.067 * *$ & $.071^{* * *}$ & $.060 * *$ \\
\hline & $(.028)$ & $(.026)$ & $(.023)$ & $(.026)$ \\
\hline \multirow[t]{2}{*}{ BadHealth } & $-.402^{* * *}$ & $-.389 * * *$ & $-.288^{* * *}$ & $-.375^{* * *}$ \\
\hline & $(.058)$ & $(.059)$ & $(.043)$ & $(.057)$ \\
\hline \multirow[t]{2}{*}{ Lnhrs } & $-.104^{* * *}$ & $-.221^{* * *}$ & $-.136 * * *$ & $-.218^{* * *}$ \\
\hline & $(.037)$ & $(.048)$ & $(.037)$ & $(.049)$ \\
\hline \multirow[t]{2}{*}{ HigherEdu } & .047 & -.017 & .024 & -.011 \\
\hline & $(.055)$ & $(.049)$ & $(.055)$ & $(.052)$ \\
\hline \multirow[t]{2}{*}{ SecondEdu } & .027 & .002 & .011 & .007 \\
\hline & $(.036)$ & $(.036)$ & $(.040)$ & $(.039)$ \\
\hline \multirow[t]{2}{*}{ Supervisor } & $.290^{* * *}$ & $.245^{* * *}$ & $.171^{* * *}$ & $.239 * * *$ \\
\hline & $(.053)$ & $(.045)$ & $(.040)$ & $(.045)$ \\
\hline \multirow[t]{2}{*}{ Intermediate } & $.142^{* * *}$ & $.122^{* * *}$ & $.079 * * *$ & $.118^{* * *}$ \\
\hline & $(.034)$ & $(.031)$ & $(.025)$ & $(.031)$ \\
\hline \multirow[t]{2}{*}{ Professional } & $.264^{* * *}$ & $.190^{* * *}$ & $.140 * * *$ & $.188^{* * *}$ \\
\hline & $(.046)$ & $(.034)$ & $(.023)$ & $(.037)$ \\
\hline \multirow[t]{2}{*}{ Serviceworker } & $.133^{* * *}$ & $.111^{* * *}$ & $.091^{* * *}$ & $.108^{* * *}$ \\
\hline & $(.028)$ & $(.025)$ & $(.026)$ & $(.026)$ \\
\hline \multirow[t]{2}{*}{ PubliSector } & $.184^{* * *}$ & $.155^{* * *}$ & $.103^{* * *}$ & $.156^{* * *}$ \\
\hline & $(.042)$ & $(.035)$ & $(.031)$ & $(.037)$ \\
\hline \multirow[t]{2}{*}{ FullTime } & .059 & -.023 & .005 & -.011 \\
\hline & $(.046)$ & $(.038)$ & $(.037)$ & $(.039)$ \\
\hline \multirow[t]{2}{*}{ Agriculture } & .020 & .070 & -.017 & .062 \\
\hline & $(.058)$ & $(.054)$ & $(.079)$ & $(.051)$ \\
\hline \multirow[t]{2}{*}{ Industry } & $-.050 * * *$ & $-.066^{* * *}$ & $-.085^{* * *}$ & $-.069 * * *$ \\
\hline & $(.018)$ & $(.018)$ & $(.019)$ & $(.019)$ \\
\hline \multirow[t]{2}{*}{ EPL } & .155 & .114 & .113 & .169 \\
\hline & $(.101)$ & $(.098)$ & $(.098)$ & $(.119)$ \\
\hline \multirow[t]{2}{*}{ RTE } & -.015 & $-.021^{*}$ & $-.022^{*}$ & $-.024^{*}$ \\
\hline & $(.012)$ & $(.012)$ & $(.011)$ & $(.014)$ \\
\hline \multirow[t]{2}{*}{ Lnincome } & & $.324^{* * *}$ & $.279^{* * *}$ & $.318^{* * *}$ \\
\hline & & $(.075)$ & $(.074)$ & $(.078)$ \\
\hline \multirow[t]{2}{*}{ RegUnempl } & & & & -.007 \\
\hline & & & & $(.006)$ \\
\hline Country Effects & Yes & Yes & Yes & Yes \\
\hline Year Effects & Yes & Yes & Yes & Yes \\
\hline Observations & 218765 & 218765 & 218765 & 208942 \\
\hline
\end{tabular}

a: Mudlak specification in column 3, including means of all individual-level regressors. Significance levels:* $10 \% * * 5 \% * * * 1 \%$

SE adjusted for country clusters. ECHP data, 1995-2001, all employees 16-65. 
Table 3: Random effects ordered probit estimates for regulations in the private and public sector. Job satisfaction equations for permanent employees.

\begin{tabular}{llc}
\hline \hline Variable & \multicolumn{1}{c}{$\mathbf{1}$} \\
Coef./SE & $\begin{array}{c}\mathbf{2} \\
\text { Coef./SE }\end{array}$ \\
\hline EPLPub & .118 & .176 \\
& $(.097)$ & $(.118)$ \\
EPLPriv & .106 & .166 \\
& $(.100)$ & $(.122)$ \\
RTEPubl & .019 & .017 \\
& $(.025)$ & $(.027)$ \\
RTEPriv & $-.045^{* * *}$ & $-.048^{* * *}$ \\
& $(.012)$ & $(.013)$ \\
RegUnempl & & -.007 \\
& & $(.006)$ \\
\multicolumn{2}{c}{ Controls as in column 2 of table 2} \\
\hline
\end{tabular}

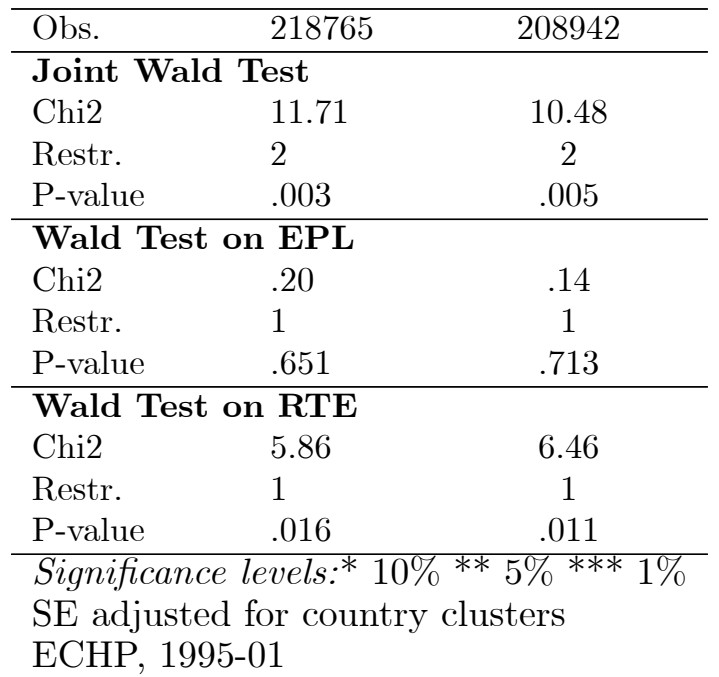


Table 4: Random effects ordered probit: job satisfaction equations for temporary employees.

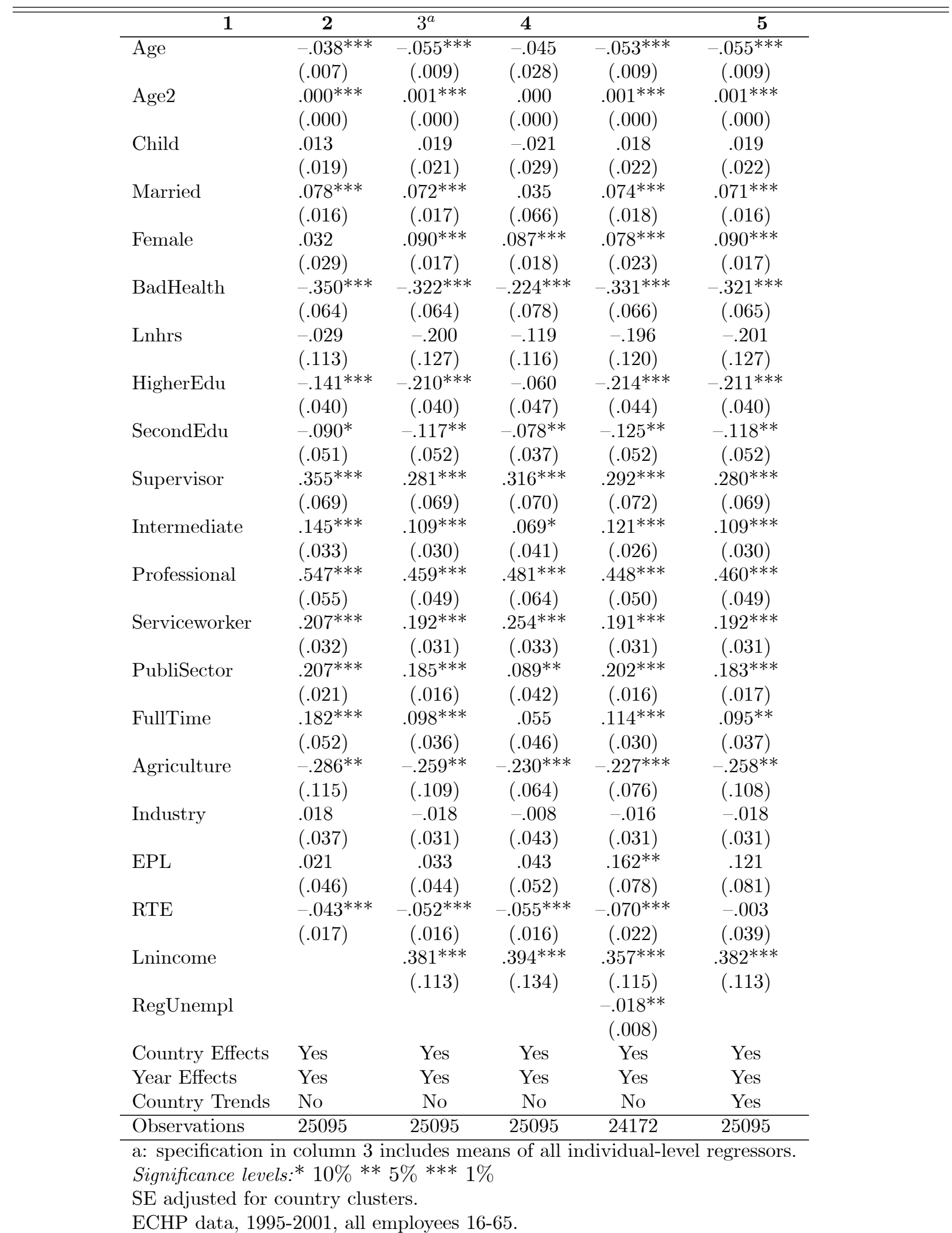


Table 5: Random effects ordered probit: job satisfaction equations for temporary employees by macro region.

\begin{tabular}{llc|cc}
\hline \hline & \multicolumn{1}{c}{$\mathbf{1}$} & $\mathbf{2}$ & $\mathbf{3}$ & $\mathbf{4}$ \\
& South incl. France & North & South & North incl. France \\
\hline EPL & $.114^{* * *}$ & -.101 & $.094^{*}$ & -.093 \\
& $(.020)$ & $(.170)$ & $(.050)$ & $(.107)$ \\
RTE & $-.038^{* * *}$ & $-.067^{* * *}$ & $-.044^{* * *}$ & -.046 \\
& $(.009)$ & $(.023)$ & $(.008)$ & $(.028)$
\end{tabular}

\begin{tabular}{lcc|cc} 
& \multicolumn{4}{c}{ Controls as in column 2 of table 4} \\
\hline Observations & 17887 & 7208 & 15388 & 9707
\end{tabular}

Significance levels:* $10 \%$ ** $5 \%$ *** $1 \%$

SE adjusted for country clusters

ECHP data, 1995-2001, all employees aged 16-65

Table 6: Random effects ordered probit: job satisfaction equations for temporary employees by age and gender.

\begin{tabular}{lcccc}
\hline \hline & Men & Women & Young & Adults \\
\hline EPL & .026 & .077 & .039 & .087 \\
& $(.059)$ & $.087)$ & $(.074)$ & $(.088)$ \\
RTE & -.011 & $-.090^{* * *}$ & $-.069^{* * *}$ & $-.034^{*}$ \\
& $(.025)$ & $(.029)$ & $(.027)$ & $(.020)$
\end{tabular}

Controls as in column 2 of table 4

\begin{tabular}{lllll}
\hline Observations & 13196 & 11899 & 12588 & 12507 \\
\hline
\end{tabular}

Significance levels:* $10 \%$ ** 5\% *** $1 \%$

SE adjusted for country clusters

ECHP data, 1995-2001, all employees aged 16-65 
Table 7: Random effects ordered probit: satisfaction with security equations for temporary employees.

\begin{tabular}{|c|c|c|c|c|}
\hline & All & All & Men & Women \\
\hline Age & $\begin{array}{l}-.084^{* * *} \\
(.015)\end{array}$ & $\begin{array}{c}-.079^{* * *} \\
(.014)\end{array}$ & $\begin{array}{c}-.085^{* * *} \\
(.014)\end{array}$ & $\begin{array}{c}-.082^{* * *} \\
(.018)\end{array}$ \\
\hline Age2 & $\begin{array}{l}.001^{* * *} \\
(.000)\end{array}$ & $\begin{array}{c}.001^{* * *} \\
(.000)\end{array}$ & $\begin{array}{c}.001^{* * *} \\
(.000)\end{array}$ & $\begin{array}{c}.001^{* * *} \\
(.000)\end{array}$ \\
\hline Child & $\begin{array}{l}-.053^{* *} \\
(.024)\end{array}$ & $\begin{array}{c}-.047^{* *} \\
(.024)\end{array}$ & $\begin{array}{c}-.055^{* *} \\
(.023)\end{array}$ & $\begin{array}{c}-.049 \\
(.039)\end{array}$ \\
\hline Married & $\begin{array}{l}.026 \\
(.022)\end{array}$ & $\begin{array}{c}.034 \\
(.023)\end{array}$ & $\begin{array}{c}.020 \\
(.037)\end{array}$ & $\begin{array}{c}.041 \\
(.029)\end{array}$ \\
\hline Female & $\begin{array}{l}-.057 \\
(.037)\end{array}$ & $\begin{array}{c}-.076^{* *} \\
(.031)\end{array}$ & & \\
\hline BadHealth & $\begin{array}{l}-.238^{* * *} \\
(.050)\end{array}$ & $\begin{array}{c}-.246^{* * *} \\
(.049)\end{array}$ & $\begin{array}{c}-.275^{* * *} \\
(.073)\end{array}$ & $\begin{array}{c}-.207^{* *} \\
(.088)\end{array}$ \\
\hline Lnincome & $\begin{array}{l}.225^{* * *} \\
(.064)\end{array}$ & $\begin{array}{c}.189^{* * *} \\
(.060)\end{array}$ & $\begin{array}{c}.243^{* * *} \\
(.060)\end{array}$ & $\begin{array}{l}.145^{* *} \\
(.069)\end{array}$ \\
\hline Lnhrs & $\begin{array}{l}.042 \\
(.056)\end{array}$ & $\begin{array}{c}.036 \\
(.057)\end{array}$ & $\begin{array}{c}.240 * * * \\
(.082)\end{array}$ & $\begin{array}{c}-.147^{* * *} * \\
(.054)\end{array}$ \\
\hline HigherEdu & $\begin{array}{l}-.228^{* * *} \\
(.062)\end{array}$ & $\begin{array}{c}-.246^{* * *} \\
(.063)\end{array}$ & $\begin{array}{c}-.225^{* * *} \\
(.068)\end{array}$ & $\begin{array}{c}-.262^{* * *} \\
(.074)\end{array}$ \\
\hline SecondEdu & $\begin{array}{l}-.116^{* *} \\
(.054)\end{array}$ & $\begin{array}{c}-.128^{* *} \\
(.054)\end{array}$ & $\begin{array}{c}-.117^{*} \\
(.069)\end{array}$ & $\begin{array}{c}-.147^{* * * *} \\
(.045)\end{array}$ \\
\hline Supervisor & $\begin{array}{l}.462^{* * *} \\
(.103)\end{array}$ & $\begin{array}{c}.465^{* * *} \\
(.110)\end{array}$ & $\begin{array}{c}.467^{* * *} \\
(.109)\end{array}$ & $\begin{array}{c}.441^{* * *} \\
(.156)\end{array}$ \\
\hline Intermediate & $\begin{array}{l}.157^{* * *} \\
(.025)\end{array}$ & $\begin{array}{c}.162^{* * *} \\
(.026)\end{array}$ & $\begin{array}{c}.183^{* * *} \\
(.031)\end{array}$ & $\begin{array}{c}.132^{* * *} \\
(.045)\end{array}$ \\
\hline Professional & $\begin{array}{l}.179 * * * \\
(.041)\end{array}$ & $\begin{array}{c}.180 * * * \\
(.043)\end{array}$ & $\begin{array}{l}.177^{* *} \\
(.083)\end{array}$ & $\begin{array}{c}.184^{* * *} \\
(.047)\end{array}$ \\
\hline Serviceworker & $\begin{array}{l}.158^{* * *} \\
(.033)\end{array}$ & $\begin{array}{l}.156^{* * *} \\
(.034)\end{array}$ & $\begin{array}{c}.162^{* * *} \\
(.035)\end{array}$ & $\begin{array}{c}.161^{* * *} \\
(.054)\end{array}$ \\
\hline PubliSector & $\begin{array}{l}-.180^{* * *} \\
(.031)\end{array}$ & $\begin{array}{c}-.160^{* * *} \\
(.032)\end{array}$ & $\begin{array}{c}-.142^{* * *} \\
(.046)\end{array}$ & $\begin{array}{c}-.162^{* * *} \\
(.037)\end{array}$ \\
\hline FullTime & $\begin{array}{l}-.075 \\
(.069)\end{array}$ & $\begin{array}{l}-.046 \\
(.072)\end{array}$ & $\begin{array}{l}-.080 \\
(.099)\end{array}$ & $\begin{array}{c}.048 \\
(.083)\end{array}$ \\
\hline Agriculture & $\begin{array}{l}-.199 * * * \\
(.062)\end{array}$ & $\begin{array}{c}-.142^{* * *} \\
(.039)\end{array}$ & $\begin{array}{c}-.163^{* *} \\
(.072)\end{array}$ & $\begin{array}{l}-.101 \\
(.087)\end{array}$ \\
\hline Industry & $\begin{array}{l}-.090^{* * *} \\
(.033)\end{array}$ & $\begin{array}{c}-.093^{* * *} \\
(.035)\end{array}$ & $\begin{array}{c}-.097^{* *} \\
(.038)\end{array}$ & $\begin{array}{c}-.086^{* *} \\
(.039)\end{array}$ \\
\hline EPL & $\begin{array}{l}.209 \\
(.128)\end{array}$ & $\begin{array}{c}.376^{* * *} \\
(.126)\end{array}$ & $\begin{array}{c}.339^{* * *} \\
(.106)\end{array}$ & $\begin{array}{l}.475^{* *} \\
(.195)\end{array}$ \\
\hline RTE & $\begin{array}{l}.027 \\
(.041)\end{array}$ & $\begin{array}{l}-.003 \\
(.040)\end{array}$ & $\begin{array}{c}.050 \\
(.038)\end{array}$ & $\begin{array}{l}-.050 \\
(.048)\end{array}$ \\
\hline RegUnempl & & $\begin{array}{c}-.025^{* * *} \\
(.010)\end{array}$ & $\begin{array}{c}-.029 * * * \\
(.008)\end{array}$ & $\begin{array}{c}.019^{*} \\
(.011)\end{array}$ \\
\hline Country Effects & Yes & Yes & Yes & Yes \\
\hline Year Effects & Yes & Yes & Yes & Yes \\
\hline Observations & 25018 & 24097 & 12711 & 11386 \\
\hline
\end{tabular}


Table 8: Random effects ordered probit: satisfaction equations for temporary employees.

\begin{tabular}{clc}
\hline \hline & \multicolumn{1}{c}{$\mathbf{1}$} \\
EPL & Conditions & $\begin{array}{c}\mathbf{2} \\
\text { Type of Work }\end{array}$ \\
& $.234^{* * *}$ & $.139^{*}$ \\
RTE & $(.066)$ & $(.081)$ \\
& .002 & -.002 \\
& $(.019)$ & $(.016)$ \\
& Controls as in column 2 of table 4
\end{tabular}

\begin{tabular}{|c|c|c|}
\hline Observations & 24186 & 25100 \\
\hline
\end{tabular}

SE adjusted for country clusters

ECHP data, 1995-2001, all employees aged 16-65

Table 9: Random effects ordered probit estimates for regulations in the private and public sector. Job satisfaction equations for temporary employees.

\begin{tabular}{|c|c|c|c|c|}
\hline & \multicolumn{2}{|c|}{ Job Satisfaction } & \multicolumn{2}{|c|}{ Security Sat } \\
\hline & 1 & 2 & 3 & 4 \\
\hline \multirow[t]{2}{*}{ EPLPub } & .012 & $.143^{*}$ & .188 & $.348^{* *}$ \\
\hline & $(.048)$ & $(.077)$ & $(.141)$ & $(.137)$ \\
\hline \multirow[t]{2}{*}{ EPLPriv } & .031 & $.160^{*}$ & $.211^{*}$ & $.381^{* * *}$ \\
\hline & $(.049)$ & $(.082)$ & $(.126)$ & $(.123)$ \\
\hline \multirow[t]{2}{*}{ RTEPubl } & -.021 & -.038 & .047 & .019 \\
\hline & $(.016)$ & $(.025)$ & $(.048)$ & $(.046)$ \\
\hline \multirow[t]{2}{*}{ RTEPriv } & $-.068^{* * *}$ & $-.086^{* * *}$ & .017 & -.014 \\
\hline & $(.020)$ & $(.023)$ & $(.041)$ & $(.038)$ \\
\hline \multirow{2}{*}{\multicolumn{2}{|c|}{ RegUnempl }} & $-.019 * *$ & & $-.026 * * *$ \\
\hline & & $(.008)$ & & $(.010)$ \\
\hline \multicolumn{5}{|c|}{ Controls as in column 2 of table 4} \\
\hline Observations & 25095 & 24172 & 25018 & 24097 \\
\hline \multicolumn{5}{|c|}{ Joint Wald Test } \\
\hline Chi2 & 7.85 & 7.70 & 1.74 & 2.30 \\
\hline Restr. & 2 & 2 & 2 & 2 \\
\hline $\mathrm{P}$-value & .020 & .021 & .420 & .316 \\
\hline \multicolumn{5}{|c|}{ Wald Test on EPL } \\
\hline Chi2 & 1.10 & .78 & .42 & .90 \\
\hline Restr. & 1 & 1 & 1 & 1 \\
\hline P-value & .294 & .377 & .517 & .342 \\
\hline \multicolumn{5}{|c|}{ Wald Test on RTE } \\
\hline Chi2 & 7.45 & 7.58 & 1.42 & 1.50 \\
\hline Restr. & 1 & 1 & 1 & 1 \\
\hline $\mathrm{P}$-value & .006 & .006 & .233 & .221 \\
\hline
\end{tabular}

SE adjusted for country clusters

ECHP data, 1995-2001, all employees aged 16-65 


\section{References}

Addison, J. T., Teixeira, P., 2003. The economics of employment protection. Journal of Labor Research $24(1)$.

Algan, Y., Cahuc, P., 2006a. Civic attitudes and the design of labor market institutions: Which countries can implement the danish flexicurity model? IZA Discussion Papers 1928, Institute for the Study of Labor (IZA).

Algan, Y., Cahuc, P., 2006b. Job protection: The macho hypothesis. Oxford Review of Economic Policy $22(3), 390-410$.

Argyle, M., 2001. The Psycologhy of Happiness. Routledge.

Arulampalam, W., Booth, A. L., 1998. Training and labour market flexibility: Is there a trade-off? British Journal of Industrial Relations 36, 521-536(16).

URL http://www .ingentaconnect.com/content/bpl/bjir/1998/00000036/00000004/art00001

Arulampalam, W., Booth, A. L., Bryan, M. L., 2004. Training in Europe. Journal of the European Economic Association 2 (2-3), 346-360.

URL http://www.mitpress journals.org/doi/abs/10.1162/154247604323068041

Bardasi, E., Francesconi, M., 2004. The impact of atypical employment on individual wellbeing: evidence from a panel of British workers. Social Science and Medicine 58 (9), 1671 - 1688.

Blanchard, O., Landier, A., 2002. The perverse effects of partial labour market reform: fixed-term contracts in France. Economic Journal 112 (480), F214-F244.

Blanchard, O., Wolfers, J., 2000. The role of shocks and institutions in the rise of European unemployment: The aggregate evidence. Economic Journal 110 (462), C1-33.

Blanchflower, D. G., Oswald, A. J., 2004. Well-being over time in Britain and the USA. Journal of Public Economics 88 (7-8), 1359-1386.

Blanchflower, D. G., Oswald, A. J., May 2005. The wage curve reloaded. NBER Working Papers 11338, National Bureau of Economic Research, Inc.

Boeri, T., Conde-Ruiz, J. I., Galasso, V., 2003. Protecting against labour market risk: Employment protection or unemployment benefits? IZA Discussion Papers 834, Institute for the Study of Labor (IZA).

Booth, A. L., Francesconi, M., Frank, J., June 2002. Temporary jobs: Stepping stones or dead ends? Economic Journal 112 (480), F189-F213.

URL http://ideas.repec.org/a/ecj/econjl/v112y2002i480pf189-f213.html

Brunello, G., Garibaldi, P., Wasmer, E., 2007. Education and Training in Europe. Oxford University Press, Oxford.

Brügemann, B., 2007. Employment protection: Tough to scrap or tough to get? Economic Journal 117 (521), 386-415.

Cahuc, P., Postel-Vinay, F., 2002. Temporary jobs, employment protection and labor market performance. Labour Economics 9 (1), 63-91.

Cahuc, P., Zylberberg, A., 2004. Labor Economics. MIT Press, Cambridge, MA.

Clark, A., Postel-Vinay, F., 2009. Job security and job protection. Oxford Economic Papers 61 (2), 207-239.

Clark, A. E., 2001. What really matters in a job? Hedonic measurement using quit data. Labour Economics 8 (2), 223-242. 
Clark, A. E., 2003. Unemployment as a social norm: Psychological evidence from panel data. Journal of Labor Economics 21 (2), 289-322.

Clark, A. E., Oswald, A. J., 1996. Satisfaction and comparison income. Journal of Public Economics $61(3), 359-381$.

D'Addio, A. C., Eriksson, T., Frijters, P., 2007. An analysis of the determinants of job satisfaction when individuals' baseline satisfaction levels may differ. Applied Economics 39 (19), 2413-2423.

Di Tella, R., MacCulloch, R., 2006. Some uses of happiness data in economics. Journal of Economic Perspectives 20 (1), 25-46.

Di Tella, R., MacCulloch, R. J., Oswald, A. J., 2001. Preferences over inflation and unemployment: Evidence from surveys of happiness. American Economic Review 91 (1), 335-341.

Dolado, J. J., Garcia-Serrano, C., Jimeno, J. F., 2002. Drawing lessons from the boom of temporary jobs in Spain. Economic Journal 112 (721), F270-F295.

Easterlin, R. A., 2001. Income and happiness: Towards an unified theory. Economic Journal 111 (473), $465-84$.

Ferrer-i Carbonell, A., 2005. Income and well-being: an empirical analysis of the comparison income effect. Journal of Public Economics 89 (5-6), 997-1019.

Freeman, R., 2005. Labour market institutions without blinders: The debate over flexibility and labour market performance. International Economic Journal 19 (2), 129-145.

Freeman, R. B., 1978. Job satisfaction as an economic variable. American Economic Review 68 (2), $135-41$.

Frey, B. S., Stutzer, A., 2002. What can economists learn from happiness research? Journal of Economic Literature 40 (2), 402-435.

Greene, W. H., 2007. Econometric Analysis, 6th Edition. Pearson Prentice Hall.

Hamermesh, D., 2001. The changing distribution of job satisfaction. Journal of Human Resources, 1-30.

Heywood, J. S., Siebert, W. S., Wei, X., 2002. Worker sorting and job satisfaction: The case of union and government jobs. Industrial and Labor Relations Review 55 (4), 595-609.

Kahn, L. M., 06 2007. The impact of employment protection mandates on demographic temporary employment patterns: International microeconomic evidence. Economic Journal 117 (521), 333-356.

Kahn, L. M., forthcoming. Employment protection reforms, employment and the incidence of temporary jobs in europe: 1995Ü2001. Labour Economics.

Kahneman, D., Krueger, A. B., Winter 2006. Developments in the measurement of subjective well-being. Journal of Economic Perspectives 20 (1), 3-24.

URL http://ideas.repec.org/a/aea/jecper/v20y2006i1p3-24.html

Layard, R., 03 2006. Happiness and public policy: a challenge to the profession. Economic Journal 116 (510), C24-C33.

Luttmer, E. F. P., 2005. Neighbors as negatives: Relative earnings and well-being. The Quarterly Journal of Economics 120 (3), 963-1002.

Lévy-Garboua, L., Montmarquette, C., Simonnet, V., 2007. Job satisfaction and quits. Labour Economics $14(2), 251-268$.

Mundlak, Y., 1978. On the pooling of time series and cross section data. Econometrica 46 (1), 69-85. 
Nicoletti, G., Scarpetta, S., Boylaud, O., Apr. 2000. Summary indicators of product market regulation with an extension to employment protection legislation. Oecd economics department working papers, OECD, Economics Department.

OECD, 1999. Employment Outlook. OECD, Paris.

OECD, 2002. Employment Outlook. OECD, Paris.

OECD, 2004. Employment Outlook. OECD, Paris.

Peracchi, F., 2002. The European community household panel: A review. Empirical Economics 27 (1), 63-90.

Petrongolo, B., 2004. Gender segregation in employment contracts. Journal of the European Economic Association 2 (2-3), 331-345.

Pissarides, C., 2000. Equilibrium unemployment theory. Cambridge: MIT press.

Rabe-Hesketh, S., Skrondal, A., Pickles, A., Oct. 2004. Gllamm manual. U.C. Berkeley Division of Biostatistics Working Paper Series 1160, Berkeley Electronic Press.

Saint-Paul, G., 2002. The political economy of employment protection. Journal of Political Economy $110(3), 672-701$.

Tella, R. D., MacCulloch, R. J., Oswald, A. J., 2003. The macroeconomics of happiness. The Review of Economics and Statistics 85 (4), 809-827.

Vendrik, M. C., Woltjer, G. B., 2007. Happiness and loss aversion: Is utility concave or convex in relative income? Journal of Public Economics 91 (7-8), 1423 - 1448.

Warr, P., 1999. Wellbeing and the workplace. New York: Russell Sage Foundation.

Wasmer, E., 1999. Competition for jobs in a growing economy and the emergence of dualism. Economic Journal 109 (457), 349-71.

Wasmer, E., Nov. 2006. The economics of prozac: Do employees really gain from strong employment protection? IZA Discussion Papers 2460, Institute for the Study of Labor (IZA).

Wooldridge, J. M., 2003. Cluster-sample methods in applied econometrics. American Economic Review 93 (2), 133-138. 